\title{
Post 2008 Olympics: Has The Spotlight Left China And Beijing For Good Or Will There Be A Continuing Impact On Tourism And The Economy As A Result?
}

Kathleen M. Premo, St. Bonaventure University, USA

\begin{abstract}
The enormous investment by China in the 2008 Summer Olympics in Beijing has paid dividends in terms of lavish world attention that was directed at Beijing and China during the summer of 2008. It has been scarcely three decades since China's economy was opened to the point where China is on the threshold of becoming the world's third-largest economy. Travel and tourism can certainly continue to positively impact the economy of this country. As for tourists, China has much to offer and is quickly catching up with the rest of the world; cities such as Beijing and Shanghi in the eastern part of the country call attention to the success of the government's economic development in that area. Rapid development of infrastructure in those cities is on par or has rivaled development in many other large metropolitan cities located throughout the world. Yet much of the western part of the country still provides unparalleled access to exotic cultures, beautiful landscapes, and tranquil scenery. Increasing numbers of tourists from the rest of the world seem anxious to experience China, before it changes. The world has been witness to rapid economic growth and the Chinese government is focusing on making tourism an important developmental strategy. This paper will attempt to identify the problems relating to China's emergence from its mainly agricultural society to the point where it is today and will consider the boost in interest that was created as a result of the 2008 Beijing Olympics.
\end{abstract}

Keywords: Olympics, Beijing, China, tourism, travel

\section{INTRODUCTION}

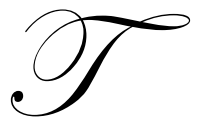

he summer 2008 Olympics Games were, in many respects, a "win" for China and have provided China and Beijing with a positive legacy. As was the goal of many of the past Olympics, the sponsoring country's international profile has risen, at least for the short term. According to IOC President Jacques Rogge, once the games were awarded to China in 2001, the preparations that preceded the actual Olympics resulted in an improved transportation infrastructure, a more aggressive approach to curbing air pollution and other environmental problems, and more grass-roots interest in recreational sports (Crary 2008). To that end, the costs for funding the Olympics were staggering; $\$ 40$ billion was spent on infrastructure and a $\$ 2.1$ billion operating budget plus the millions that the government spent on ensuring its athletes would successfully represent the nation (Blount 2008). Nineteen new venues for the events were constructed, the capacity of the subway was doubled, and a new terminal capable of handling sixty million passengers a year was added. The government not only launched etiquette campaigns forbidding spitting, smoking, littering, and cutting in line but also introduced programs to teach English to cab drivers, police officers, hotel workers, and waiters. Beijing officials used projects as a means to refurbish decaying buildings and reduce air pollution, water shortages, and traffic jams (Economy and Segal 2008). 
The Olympic Games provided an opportunity for the world to learn more about China and for China to learn more about the world. Yet, in the midst of the Olympics, more criticism was directed at China as indicated by the U.S. Embassy located in China, "China should have used its moment in the global spotlight to show greater tolerance and openness" (Crary 2008). Many feel that the games did little to lessen concerns about China's position on human rights. Even though media restrictions were less intense during the Olympics, many Olympic visitors returned to their respective countries with the realization that, despite promises of press freedom during the games, the government continued to block numerous politically oriented Web sites, including those related to Tibet and increased political repression. Visitors to Beijing today do not even have access to media outlets such as $\mathrm{CNN}$ and the BBC.

The Beijing Olympics were supposed to make 2008 a banner year for travel and tourism in China. The Chinese government's plan was to turn Beijing into a center for international visitors that governmental officials hoped would increase tourism for other Chinese destinations, but along the way problems occurred. The massive earthquake in Sichuan province, ethnic unrest in Tibet, new visa restrictions, and rising inflation have turned off many leisure travelers who are apparently postponing trips to China until problems diminish. Chinese travel companies indicate that they are reeling from cancellations and delays by foreign tourists backing away because of security and visa concerns. Even though Beijing is often chosen by many travelers as their primary Chinese travel venue, a number of the more exotic destinations such as Tibet, parts of Sichuan, Qinghai and Gansu provinces were declared off limits throughout the summer and were inaccessible by travelers. These areas contain rugged terrains that are usually major tourist attractions and are linked by rail that was completed in 2006 (Loew and Cheng 2008). A Chinese travel/booking agency, Jinjiang Travel, indicated that inbound tourism in the first half of 2008 had already plunged at least $60 \%$ from 2007; many cancellations have been by Japanese and other Asians (Leow and Cheng 2008).

At this time, fewer people may be applying for visas because of the perception that it is more difficult to get visas. The Chinese government has indicated that it has tightened the visa policy this year for what was deemed security reasons (Leow and Cheng 2008). Observers have felt that the new policy was a method the government used to keep out foreign protesters and opponents of China, particularly before and during the Olympics.

Inflation is another factor that is discouraging travel to China by tourists. Recently, the yuan has risen against the American dollar and inflation in China is problematic. The cost of dining in restaurants rose dramatically within the year preceding the Olympics.

Perhaps the most glaring and serious problem awaiting visitors is air quality in major cities (including Beijing) on the eastern coast of China. The pollution levels in Beijing are still far above average. On a typical day, the city's air pollution is three times as bad as the standard deemed safe by the World Health Organization (Economy and Segal 2008). Just a year before the Olympics, an air-quality test revealed that pollution levels in Beijing had barely improved despite one-third of the cars having been removed from the city's roads. More concerns for tourists include Beijing's (and, for that matter, all of China's) capacity to provide safe and clean water. In the past 18 months, China has endured a rash of scandals involving food tainted with steroids and insecticides, and as much as half of the bottled water in Beijing does not meet potable-water standards. (Economy and Segal 2008). In late summer of 2008, more bad news hit the international press in terms of tainted baby formula that had caused numerous infant deaths in China.

Before one could conclude that there is an effect that the Olympic Games have had on China's tourism, it is important to take a look at the impact that tourism is having on China. Previous research conducted by Feng (2008) points to many of the socioecological costs resulting from growth of the tourism industry. Feng's research draws attention to the actual impact of the capital-intensive development model on local people in Western China. She concluded that the development of tourist infrastructures is left largely to the interplay of market forces. The outcome is that this interplay fails to ensure that adequate attention will be devoted to environmental resources, social impacts, and conflicts of interest among developers, local residents, and tourists (Feng 2008). As Feng noted, since tourism began to be developed in Fenghuany County located in Southwest China, the infrastructure has been unable to cope with the intensity and impact of tourists. Results have included increases in pollution, over-burdened 
electricity, social changes including changes in value systems, traditional lifestyles, women's roles, community cohesion, and social tension (Feng 2008).

Few today would question China's future in the world - politically, socially, and economically. China began opening its economy only three decades ago and, in the aftermath, it has been able to bring more of its people out of poverty than any other nation in the modern world. For many of us in the U.S., little is known about China and the Games were an engaging opportunity for China to be presented to the world. Increased interest in visiting China might not have been considered by many had it not been for weeks of television and print coverage leading up to and during the Olympics that provided serene photos of a distant country seemingly caught in time. The government did its job of polishing its image and that image was well-received. Many viewers spent hours in front of their televisions and reading daily newspapers, anxious to get a glimpse of a culture existing today, half-wayaround the world.

\section{LITERATURE REVIEW}

Baade and Matheson (2002) point out that in a less-developed country (such as China), the opportunity costs of providing state-of-the art facilities and the lack of modern infrastructure require a significant additional investment. The very fact that an enormous amount of money was poured into changing the facilities and infrastructure surrounding the Beijing Olympics has obviously had an impact on the area. But, Baade and Matheson (2002) further suggested that the investment in state-of-the-art facilities may not (have been) a wise investment from a social welfare standpoint in China. Research by Owen (2005)further states that most people assume that such an event will bring enormous economic benefits to the host city not just during the event, but for years afterward. However, Owen (2005) noted that ex-post studies have consistently found no evidence of positive economic impacts from mega-sporting events even remotely approaching the estimates in economic impact. Further, Owen (2005) noted that in the case of the Sydney Olympics, plans were in place for long-term use of many of its venues. Four years after the Sydney Olympics, the arena that housed gymnastics and basketball was in receivership (Owen 2005). In his research, Philip Porter (1999) found no measurable impact on spending associated with an event of the magnitude of the Olympics. He also found the projected spending and spillover benefits of regional impact models never materialize (Porter 1999). These studies contradict the typical assumption that the city holding the Olympic Games will reap huge economic benefits.

Projections of growth in travel and tourism seem to paint a positive picture for the future of China. Refer to Table 1 prepared by the Economist Intelligence Unit that predicts incremental growth in China's international tourism. The increase in arrivals in 2008, and the numbers projected for 2009 (although the numbers do reflect a projected incremental growth) do not seem affected by a spike in the increase of tourism concurrent and following the Olympics(Two-Way Traffic 2008).

Table 1

\begin{tabular}{|l|c|c|c|c|c|c|}
\hline \multicolumn{7}{|c|}{ China: travel and tourism forecast } \\
\hline & $\mathbf{2 0 0 7}$ & $\mathbf{2 0 0 8}$ & $\mathbf{2 0 0 9}$ & $\mathbf{2 0 1 0}$ & $\mathbf{2 0 1 1}$ & $\mathbf{2 0 1 2}$ \\
\hline International tourism, arrivals ('000) & 52,901 & 55,954 & 59,605 & 63,542 & 67,861 & 72,477 \\
\hline International tourism, departures ('000) & 40,388 & 46,314 & 53,019 & 60,217 & 68,031 & 76,631 \\
\hline International tourism, expenditure (US\$m) & 38,146 & 48,979 & 59,813 & 72,762 & 87,327 & 104,450 \\
\hline International tourism, receipts (US\$m) & 43,114 & 66,614 & 68,178 & 80,540 & 90,039 & 105,637 \\
\hline Consumer expenditure: hotels \& restaurants (US\$m) & 57,511 & 73,034 & 88,052 & 106,966 & 129,619 & 157,493 \\
\hline Source: Economist Intelligence Unit
\end{tabular}

(Two-Way Traffic 2008)

Even more dramatic in this table is the growing number of international tourism departures which is due in part to an increasingly affluent middle class of Chinese who can afford to travel outside China. The table also tends 
to reinforce the reality of an economic impact of tourism in terms of money spent by tourists entering and leaving the country.

\section{THE CHINESE GOVERNMENT'S POSITION IN ADDRESSING PROBLEMS}

The Chinese government is making tourism an important rural developmental strategy.

Local governments and outside developers jointly manage and develop natural and cultural resources to increase tourism revenues (Feng 2008). But there are problems that China must quickly face and deal with if it wants to capitalize on the world's eagerness to visit China. Its problems with pollution, the continuing problem with conflict in Tibet, and travelers' concerns about safe food and water are looming in tourists' minds as evidenced by the tourism industry experiencing a decline during the first five months of 2008 , its first since 2005 . Hotel occupancy in 2008 across China decreased to 59.3 percent compared to 64.4 percent for the same period of the previous year (Baran 2008). The number of inbound tourists per year staying at least one night was expected to reach 100 million by 2015, from 54 million people in 2007 (Chan 2008). Revenue from the tourism industry may reach two trillion yuan and account for $4.8 \%$ of the country's gross domestic product by 2015, from 1.09 trillion yuan and $4.4 \%$ of GDP in 2007, according to the China National Tourism Administration forecasts (Chan 2008). Chinese authorities are increasingly worried that a lack of tourism is hurting Tibet's economy and, for that reason, the government plans to let foreign tourists back into Tibet. Tibet's tourism revenue last year made up $14 \%$ of its gross domestic product, according to the Xinhua news agency (Leow 2008). Parts of the Sichuan province were closed to foreigners after Lhasa riots and, although open to Chinese, the areas have been closed to foreign travelers (Leow 2008).

\section{CONCLUSION}

China is definitely ripe for growth in its tourism industry while strong growth in this area is expected to continue in coming years. Certainly the tourist attractions in China are highly prized. This being said, it begs the question posed in this paper, "Will there be a continuing impact on the economy and tourism as a result of the Beijing Olympics?" Owen (2005) claims the misconceptions held by many have led to the overly optimistic forecast of economic impact, which tends to be the norm. Owen (2005) also made a valid observation that the cost of constructing stadiums involves hiring construction workers and purchasing materials from local suppliers which benefits the local economy. In Beijing's case, one should consider that this is a backward-looking approach in that it looks at the production aspect of the project and ignores the effect of the actual consumption of the product (Owen 2005). Can the state-of-the-art Beijing Olympic buildings be effectively used in the future?

Baade and Matheson (2002) found the evidence suggests that the economic impact of the Olympics is transitory; one time changes rather than a steady-state-change.

The conclusion here is that tourists will come to China. The Chinese government has become more receptive to travelers and the government, at this point, realizes the importance of revenue that tourists can generate for China; the government is actively trying to bring in additional tourist revenue. The Olympics presented a wonderful portrait of China and, as for the Olympics' legacy, China pumped millions into Beijing so the city and country was certainly well-presented to the world. The cost and investment committed by the government in the Olympics certainly managed to generate pride in the citizens of China. Tourists will continue to visit China, but quite quickly those anxious to travel will realize that the lights have gone out in the Beijing Olympic stadiums and the athletes have gone home. People will visit China to see China, and, similar to what historically has occurred with other Olympic hosts, the Beijing Olympics may soon be forgotten by many.

\section{AUTHOR INFORMATION}

Kathleen M. Premo is a native of New York State and has been a faculty member at St. Bonaventure University for the last eleven years. During that time, one of the courses that she routinely teaches is International Management. 
In May 2008, she was able to travel into China, visiting Beijing, Shanghi, and Xi'an, where she was able to study the current business environment and culture of China.

\section{REFERENCES}

1. Baade, Robert A. \& Matheson, Victor. (2002). Bidding for the Olympics: Fool's Gold? Transatlantic Sport.

2. $\quad$ Baran, Michelle. (2008). Tarnished Glory. Travel Weekly. vol. 67, issue 20, pp.1-38.

3. Blount, Rachel. (2008). For China, Olympics Have Been A Win-Win-Win Situation: The Country's Investment Has Brought Home Gold and Inspired a New Age for Fans, Athletes. McClatchy-Tribune Business News.

4. Chan, Carol. (2008). China National Travel Gears Up For Expansion on Tourism Boom. South China Morning Post. p. 3.

5. Crary, David. (2008). Mixed Legacy Likely as China's Olympics Conclude. The Monitor.

6. Economy, Elizabeth C. and Segal, Adam.(2008). China's Olympic Nightmare. Foreign Affairs. vol. 87, issue 4, pp. 47-56.

7. Feng, Xianghong. (2008). Who Benefits?: Tourism Development in Fenghuang County, China. Human Organization. vol. 67, issue 2, pp. 207-220.

8. Leow, Jason. (2008). China to Reopen Tibet; Authorities Worry Lost Tourism Revenue Could Hurt Economy. The Wall Street Journal - Europe. p.31.

9. Leow, Jason and Cheng, Jonathan. (2008). China Travel Feels a Chill; Earthquake, Inflation, Ethnic Protests Undermine Tourism In The Olympics Runup. The Wall Street Journal - Eastern Edition. p. w-7.

10. Owen, Jeffrey G. (2005). Estimating the Cost and Benefit of Hosting Olympic Games: What Can Beijing Expect from Its 2008 Games? The Industrial Geographer. vol.3, issue 1, pp. 1-18.

11. Porter, Philip K. (1999). Mega-Sports Events as Municipal Investments: A Critique of Impact Analysis. Sports Economics: Current Research. ed. by John Fizel et. al.

12. Two-Way Traffic. (2008). Business China. vol. 34, issue 5, pp. 4-5. 
NOTES 